\title{
Selection of suitable location and method for installation of TDR in opencast mine-an experimental approach
}

\author{
Guntha Karthik $^{1 *}$, Singam Jayanthu ${ }^{2}$ \\ ${ }^{1}$ ECE, DST-FIST Sponsored Department, KL University, Andhrapradesh 522502, India \\ ${ }^{2}$ NIT Rourkela, Odisha 769008, India
}

Corresponding Author Email: gunthakarthik@ rocketmail.com

https://doi.org/10.18280/mmep.050319

Received: 23 May 2018

Accepted: 19 August 2018

\section{Keywords:}

time domain reflectometry (TDR),

hangwall, footwall, joint survey

\begin{abstract}
This Paper presents detailed investigation on the selection of a suitable location for installation of Time Domain Reflectometry (TDR) with selected method at mine site. TDR is becoming a widely accepted instrumentation method for monitoring slope movement. It uses an inexpensive coaxial cable as a sensor and works like a radar to locate shear planes or zones of deformation in a slope. Selection of suitable location plays a vital role to keep the instrument safely and monitoring the weak zones in mines. For the selection of a suitable location for installation of TDR in the opencast mine, the detailed joint survey was conducted in footwall and hanging wall side and also collected rock samples from the pit, simulated with the finite difference model using Fast Lagrangian Analysis of Continua (FLAC) software. Analysis of joint survey was done using Dips software and Microsoft Excel for observing the condition of discontinuities and for finding the weak zone which is more prone to slope failure. The outputs from the above analysis show the footwall of the selected mine is more prone to failure hence continuous monitoring is required for prediction of rock mass failure and footwall bench at 350RL (Reduced Level) is selected as the suitable location for installation of TDR. These investigations are part of the research project funded by the Ministry of Mines, Government of India (GOI).
\end{abstract}

\section{INTRODUCTION}

Time Domain Reflectometry is gaining widespread attention as a cost-effective method to monitor mass movements in both soil and rock. It has been used successfully for a number of years to monitor deep-seated failures in soil deposits and for monitoring many different kinds of movements in rock masses. However, its use in monitoring shallow failures in engineered cut slopes and embankments had been limited. A significant benefit of using this technology is that it can be a cost-effective means for remotely monitoring the effectiveness of slope hazard remediation measures. A TDR cable system for monitoring ground deformations and movements consists of a coaxial cable that is embedded in a borehole in the ground and is connected to a particular apparatus [1-2]. The Dongri-Buzurg (DB) mine of Manganese Ore India Limited (MOIL) is located in the border districts of Tumsar and Balaghat in Maharashtra and Madhya Pradesh, at this mine, the ore body is lensoid in shape, consisting of braunite, pyrolusite and sillimanite. The footwall strata are muscovite schist of Mansar Group, having an RMR of 40. The hang wall rocks are Tirodi biotite gneiss and quartzitic gneiss, grading into schistose rocks; the RMR for these strata is 40 . The contact between the ore body and the footwall strata is 2 to $3 \mathrm{~m}$ wide decomposed clay or phyllitic clay. The strata in a general strike in an east-west direction, with a southerly dip of $55^{\circ}$ to $60^{\circ}$. The ore body has a strike length of $500 \mathrm{~m}$, with its width varying from 6 to $35 \mathrm{~m}$, thickening towards the east. It is free of any regular jointing. The rock samples collected from MOIL mines were tested to determine the physio-mechanical properties [3]. Many bench failures have occurred in Dongri Buzurg mine of MOIL over the last few years. Hence, the continuous monitoring is required for pre-warning of rock mass failure.

\section{FIELD INVESTIGATIONS}

The data collected from the site includes a) joint dip amount / dip direction; b) joint spacing; c) condition of the discontinuities. Rock samples were collected for laboratory testing, simulation and modeling of slopes. The joint survey was conducted which gives a number of joints per meter, strike value and DIP of slopes in both hanging wall and footwall of the mine. The joint survey was conducted in five benches of footwall side between 350-310RL and four benches of hanging wall side between 329-291m RL. Analysis of Joint survey and laboratory tests results shows that the benches for footwall side are less stable; hence, they are subjected to continuous monitoring. Due to the tendency of slope failures in footwall benches, it is proposed to monitor with TDR instrument in the footwall. Joints are also observed to be favorable for instability in footwall side as compared to hang wall. The analysis of joint survey for footwall and hanging wall is shown in Figure 1(a) and 1(b).

From the analysis of joint survey using Dips software, it was clear that the failure of slope for footwall rock is wedges, due to the presence of two major set of discontinuities and hanging wall rocks are comparatively less prone to failure. Figure 2(a) and 2(b) shows the pole concentration in footwall and hanging 
wall using Dips software.

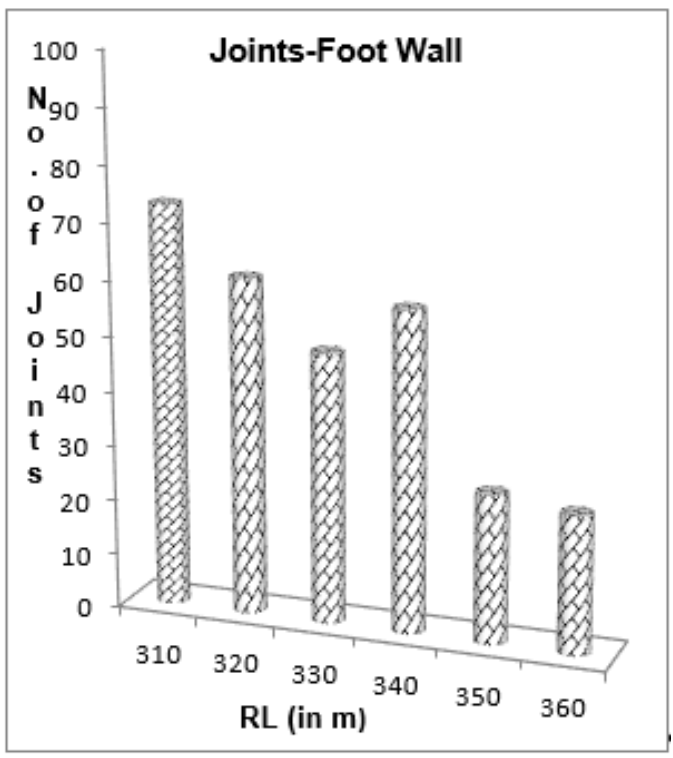

Figure 1(a). Analysis of joint survey for footwall

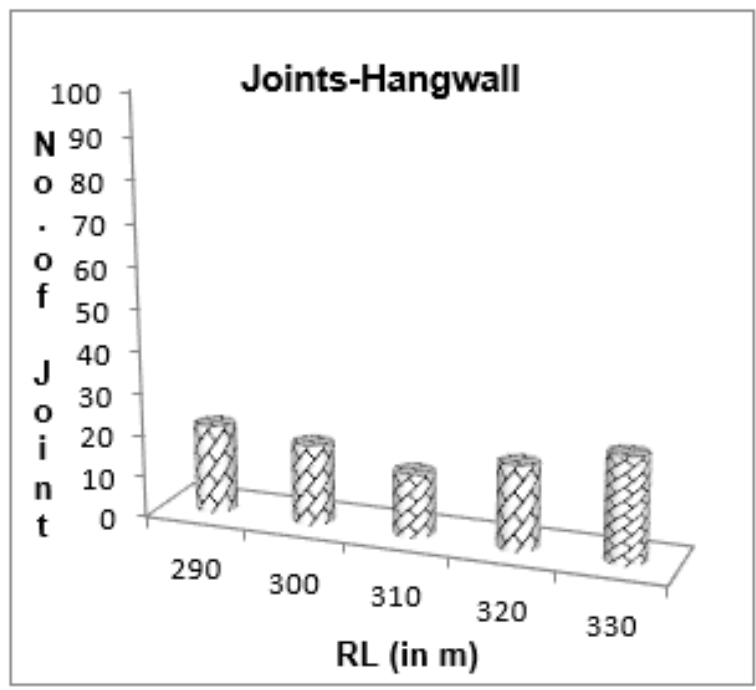

Figure 1(b). Analysis of joint survey for Hangwall
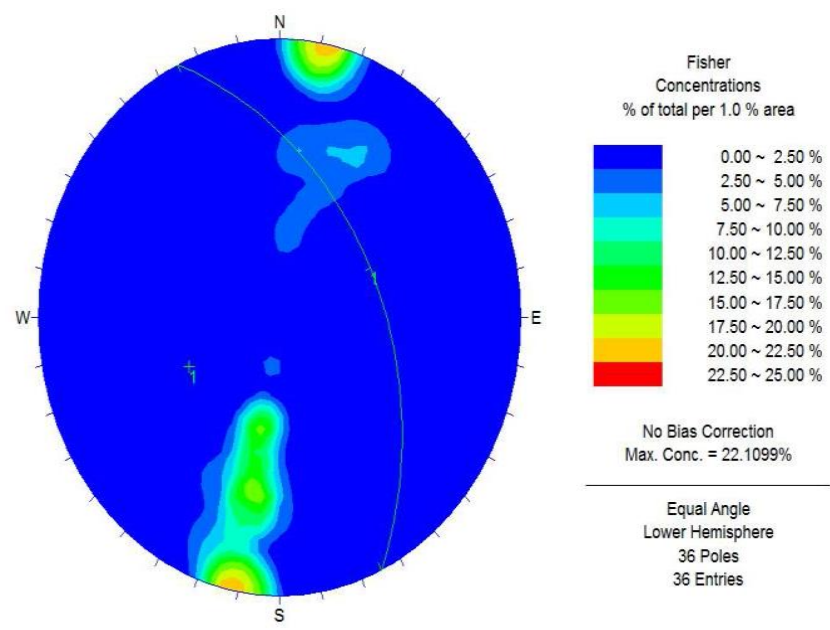

Figure 2(a). Analysis of the joint survey using the DIPS software for Footwall
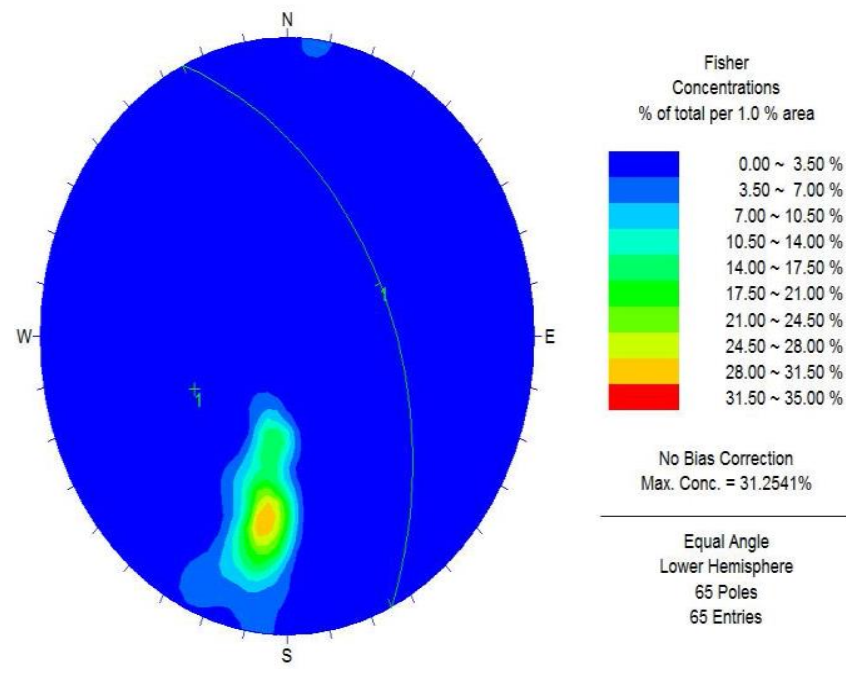

No Bias Correction Max. Conc. $=31.2541 \%$

Equal Angle

Lower Hemispher

65 Poles

65 Entries

Figure 2(b). Analysis of the joint survey using the DIPS software for Hangwall

\section{LABORATORY TEST OF COLLECTED SAMPLES}

\subsection{Testing of samples}

The samples collected from Dongri Buzurg mine of MOIL were tested in the laboratory to determine the physiomechanical properties. One sample from footwall side containing Quartz muscovite schist was taken from the collected samples since it exists in top benches of footwall side. The uniaxial compressive strength of intact rock is determined using Uniaxial Compressive Strength (UCS) test. Shear strength properties of intact rock sample were determined by triaxial testing of the above sample.

\subsection{Uniaxial testing profile \& graphical representation of properties}

Rock samples were prepared for different tests in the laboratory for determining the value of young modulus and their compressive strength mainly by Uniaxial Compressive Strength (UCS) test. Figure 3 presents the fracture profile of Quartz Muscovite Schist after completion of UCS test. The UCS has been calculated as UCS $=55 \mathrm{MPa}$ and Young's modulus $=2.5 \mathrm{GPa}$.

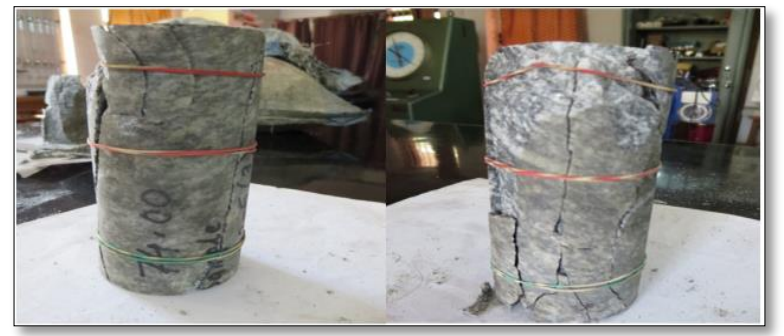

Figure 3. Fracture profile of Quartz Muscovite Schist after completion of UCS test

\subsection{Triaxial testing, profile \& Mohr's circle representation}

Triaxial testing was done to know the cohesion and angle of internal friction. There fracture profile after Triaxial testing is 
shown in Figure 4. Cohesion $=2.13 \mathrm{MPa}$, Friction angle $=$ $39.6^{0}$

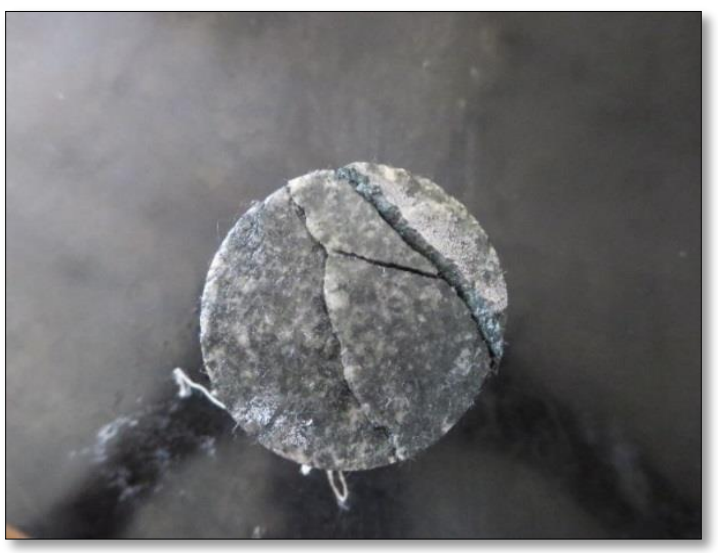

Figure 4. Fracture profile of Quartz Muscovite Schist after Triaxial test

\section{NUMERICAL MODELLING}

The numerical modelling analysis is done using FLAC-3D software[4] to understand the slope behavior and for finding the exact location for installation of TDR instrument to monitor slope movements at footwall side. The Stability analysis of footwall side was analyzed by considering the bench height $10 \mathrm{~m}$, width $15 \mathrm{~m}$, depth $100 \mathrm{~m}$, and bench angle of $62^{\circ}$. The other rock properties of Quartz Muscovite Schist are $\mathrm{UCS}=55 \mathrm{MPa}$, Young's modulus $=2.5 \mathrm{GPa}$, Cohesion $=2.13$ $\mathrm{MPa}$, and Friction angle $=39.6^{\circ}$ had taken for consideration. Figure.5 presents the stability analysis of foot wall. From above analysis, it is clear that the top three benches from $380 \mathrm{RL}$ to $350 \mathrm{RL}$ were more stable which gives the safety factor more than 4 to 4.5 .

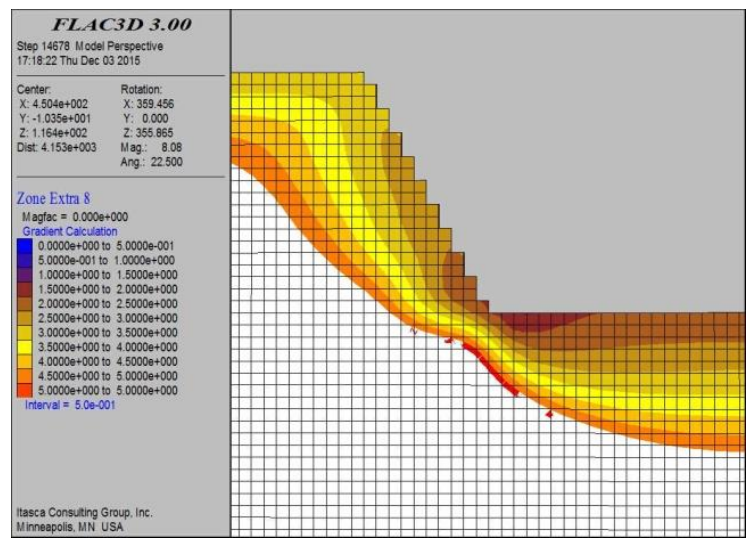

Figure 5. Stability analysis of footwall by FLAC-3D

\section{FIELD TRAIL FOR OBSERVATION OF SIGNAL LOSSES}

The field observations were done during August 2015 for analyzing the signal losses at the mine site. Complete set up of the developed system including TDR sensor unit, Power supply and the wireless transmission unit including Xbee Pro modules and Arduino mega microcontroller board took at the mine site. Figure. 6 shows the pictures taken during field trial at DB mine at the Transmitter and Receiver side of the developed wireless slope monitoring system. A testing tool is available in the XCTU software for testing the range of the XBee RF modules[5]. In this test the ease of the wireless transmission between the connected Xbee modules is tested. One of the XBee modules generates 100 no. of packets (signals), one by one and transmits it wirelessly. XCTU software continuously updates the information after transmission of each packet. Receiver Xbee provides the acknowledgment signal after receiving each of the packets. There is no problem in signal transmission from top bench i.e.390RL to 350RL (Footwall and Hanging wall). But if we go deeper than $350 \mathrm{RL}$, there is a problem in the reception of signals from 335RL to the surface. From the above field trail and the numerical modelling analysis, it is observed that 350RL of footwall side is highly stable with no further movement (development) of benches from 380RL-350RL and no signal transmission problems. Hence, 350RL is selected for the installation of our instrument for monitoring of footwall benches [7-8]. The benches above 350RL are highly stable and no further movement in that benches hence monitoring of these benches also not required.

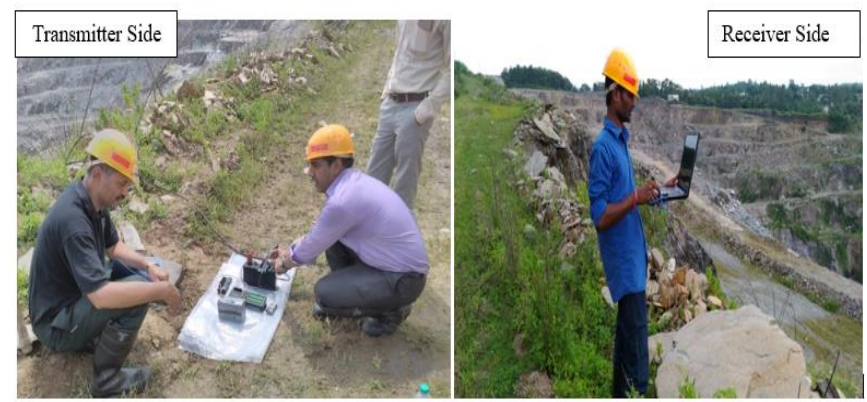

Figure 6. Range testing of communication modules at mine site

\section{METHOD FOR INSTALLATION OF INSTRUMENT AT MINE SITE}

Technically one deep hole of $80 \mathrm{~m}$ and other two holes of $20 \mathrm{~m}-25 \mathrm{~m}$ length shall be provided as it is anticipated that this will give a correct data for in-situ rock condition and slope monitoring data[6]. One $80 \mathrm{~m}$ deep hole is suitable for measuring the displacement or shifting of rock structure due to induced stresses up to the bottom of the quarry. Further, two more short holes of $20 \mathrm{~m}-25 \mathrm{~m}$ length can be drilled after stabilization of lower benches in footwall side. The three locations are marked with the total station for the installation are shown in the modified Figure.7 and Location.1,2 and 3 are as 358.21MRL,355.59MRL and 352.23MRL. RG-6 type coaxial cable will be used for installation and three coaxial cables connected to TDR through Multiplexer. This cable has been used in the field to monitor rock mass deformation with TDR. An RG-6 coaxial cable having the 75-ohm characteristic impedance and the Propagation Velocity (VP) of this cable is 0.75. The Diameter of the cable RG-6 is $8.43 \mathrm{~mm}$ and Operating temperature between $-40^{\circ} \mathrm{C}$ to $+80^{\circ} \mathrm{C}$. TDR will be connected to master node which is developed by a scientific team of National Institute of Technology (NIT) Rourkela. The Generated real-time data of TDR is directly sent to mine office through Radio Frequency (RF) module. All the electronics components such as TDR along with Multiplexer and RF 
module will be placed in a room which is specially constructed near to the cable locations, and power is also available at that location. After installation of TDR, data will be collected at TDR Room.

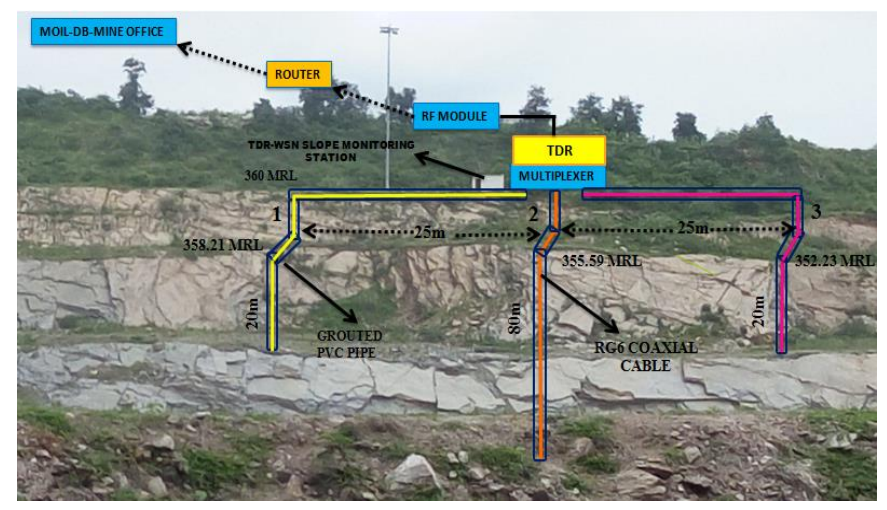

Figure 7. Installation method for the instrument at mine site with three cables and one multiplexer

\section{CONCLUSION}

The analysis of the joint survey, field visits, laboratory investigations and numerical modeling analysis shows that the footwall benches are more unstable and hang wall benches are more stable. Hence, it was concluded that continuous monitoring of footwall benches is essential for prediction of future failure. By the numerical modeling of footwall shows that the bench at $350 \mathrm{RL}$ is more stable which gives the high safety factor. The signal reception and transmission were analyzed by basic RF module in different benches from lowest $\mathrm{RL}$ to highest RL of footwall and hanging wall side, from this analysis it can be concluded that 350RL is the lowest RL where there is no signal transmission and reception problem. Hence, it is found that 350RL is selected for installation of TDR for slope stability monitoring of footwall benches in particular mine.

\section{ACKNOWLEDGEMENTS}

The authors wish to express their sincere thanks to the management of MOIL mines studied in this project. Kind cooperation and valuable suggestions were received from the mining engineers, and the senior engineers of the mines visited. NIT Rourkela is grateful to all of them.

\section{REFERENCES}

[1] Cortez ER, Hanek GL, Truebe MA, Kestler MA. (2009). Simplified User's Guide to Time-Domain-Reflectometry Monitoring of Slope Stability (No. 0877 1804 - SDTDC). Available at: https://www.fs.fed.us/td//pubs/pdf/hi_res/08771804hi.pdf, accessed on Feb. 20, 2018.

[2] Kane WF, Beck TJ. (2000). Instrumentation practice for slope monitoring. Engineering geology practice in Northern California. Association of Engineering Geologists Sacramento and San Francisco Sections 1-20.

[3] Pal L. (2015). Slope stability analysis of open cast manganese ore mine-dongri buzurg moil. diss. National Institute Of Technology Rourkela, India.

[4] FLAC/Slope 2002. (2002). User's Manual Itasca Consulting Group Inc. Minneapolis, Minnesota, America.

[5] Karthik G, Jayanthu S. (2017). Integration of TDR based radio communication system for monitoring of ground movements in open-pit mines. Disaster Advances 10(9): 34-43.

[6] Jayanthu S, Karthik G. (2017). development of effective technology for online slope monitoring in opencast mines-R \& D Initiative.

[7] Yang, PY, Wu XE, Chen JH. (2018). Blasting damage model of rock with initial damages and its application. Chemical Engineering Transactions 66: 439-444.

[8] Prashanth R, Nimaje DS. (2018). Assessment of blastinduced ground vibration using different predictor approaches-a comparison. Chemical Engineering Transactions 66: 487-492. 